\title{
PROFESSORES DA CIDADE, ALUNOS DA ROÇA: IDENTIDADES E DISCURSOS NA ESCOLA
}

\author{
Jane Adriana Vasconcelos Pacheco Rios *
}

\section{RESUMO}

Este artigo procura analisar o que dizem e o que silenciam os professores e professoras da cidade sobre os alunos e alunas da roça; como representam os alunos e as alunas da roça em suas práticas discursivas/pedagógicas. Por entender que as identidades são pontos de apego temporário às posições-de-sujeito que as práticas discursivas constroem para nós, busco analisar as práticas discursivas que se materializam na escola da cidade e que materializam as identidades dos alunos e alunas da roça, por meio da inscrição desses sujeitos nos discursos escolares dos professores e professoras, sendo este um espaço de ancoração simbólica e cambiante dos sentidos e saberes fundadores de identidades. Portanto, este texto traz práticas discursivas/pedagógicas desenvolvidas na escola da cidade, desvelando os sentidos produzidos sobre os alunos e alunas da roça por meio dos relatos dos professores e professoras do Programa Educação de Jovens e Adultos (EJA) do município de Serrolândia (BA) e pelas atividades desenvolvidas nas salas de aula, mostrando os fios discursivos tecidos na escola na "legitimação", desconstrução, contestação e negociação da identidade e dos saberes do aluno e aluna da roça que estudam na cidade.

Palavras-chave: Identidades. Discursos. Práticas docentes.

\section{ABSTRACT \\ CITY TEACHERS, COUNTRYSIDE STUDENTS: IDENTITIES AND DIRCOURSES WITHIN THE SCHOOL}

This article aims at analyzing what is said and unsaid by city teachers about countryside students, how it is portrayed the countryside students in their discursive/educational practices. Considering that identities are temporary points of attachments to subjects' position which the discursive practices set up for us, I propose to analyze the discursive practices which are materialized within city schools and which materialize the identities of countryside students through the insertion of these individuals in the school discourses of the teachers as it is seen as an area of symbolic and changing anchoring of the meanings and knowledge founders of identities. Thus, this text brings discursive/educational practices developed in city schools, unveiling the meanings produced upon countryside students through reports of the teachers of EJA (Programa de Educação de Jovens e Adultos) in Serrolândia (BA) and throughout activities

\footnotetext{
* Doutora em Educação pela Universidade Federal da Bahia. Professora Adjunta do Departamento de Ciências Humanas da Universidade do Estado da Bahia (UNEB) - Campus IV. Professora do Programa de Pós-Graduação em Educação e Contemporaneidade da Universidade do Estado da Bahia (UNEB). Endereço para contato: Uneb - Departamento de Ciências Humanas - Campus IV, Jacobina. jhanriosrios1@yahoo.com.br
} 
developed in classrooms, pointing out the discursive threads within the school in the "legitimation", deconstruction, contestation and negotiation of identity and knowledge of the countryside student who happened to study in the city.

Keywords: Identities. Discourses. Teaching practices.

\section{Introdução}

Nos diversos espaços sociais dos quais fazem parte, os alunos e alunas da roça ${ }^{1}$ deparam-se com práticas discursivas distintas. Contudo, é na escola que elas desempenham um papel maior sobre a legitimação das identidades dos alunos. Diante disto, o objetivo deste trabalho é analisar as práticas discursivas que se materializam na escola da cidade e que materializam as identidades dos alunos e alunas da roça, por meio da inscrição desses sujeitos nos discursos escolares dos professores e professoras, sendo este um espaço de ancoração simbólica e cambiante dos sentidos e saberes fundadores de identidades.

O discurso é concebido neste estudo como uma prática social, na qual nos posicionamos e somos posicionados nas/pelas práticas discursivas. Entendendo o discurso como uma produção social, é necessário levar em consideração o contexto histórico-social em que é produzido, suas condições de produção, observando como essas práticas sociais estão armazenadas em uma memória coletiva, social, institucionalizada. Desse modo, como construção social e discursiva, a identidade é uma ficção, uma ilusão, um pertencimento inventado e, sobretudo, um efeito de poder em que alguém pode falar em nome do outro, dizer quem é o outro, estabelecer o seu "regime de verdade" (FOUCAULT, 1979).

A escola da cidade estabelece uma relação de sentidos e significados na constituição da identidade dos alunos e alunas da roça, sendo um lugar concebido como contexto de construção de saberes legítimos para a sociedade letrada/científica. Nesse caso, é um local em que, pelas práticas discursivas desenvolvidas pela comunidade escolar, sobretudo pelos professores e professoras, os sujeitos aprendem a se representar e representar os outros no mundo social, assim como são representados pelos

\footnotetext{
1 A roça é concebida aqui como uma "ruralidade específica" envolta,
} principalmente, na semiótica da terra. outros em um movimento prenhe de sentidos ambivalentes adquiridos com base em outros saberes que são vivenciados fora do espaço escolar.

As identidades de alunos e alunas da roça que estudam na cidade são constituídas com base na impossibilidade de inteireza, num movimento contraditório, fluido, ambivalente na sala de aula. As práticas discursivas dos professores e professoras do Programa de Educação de Jovens e Adultos (EJA) os levam, na maioria das vezes, para um lugar contrário a isso, para uma busca de unidade identitária - há uma procura da construção do "mesmo", do homogêneo. Nesse contexto, a tendência é atribuir características singulares, únicas, idênticas, marcadas pela continuidade, pela "produção do mesmo". Assim, a "mesmidade" torna-se o sentido fundador das práticas discursivas escolares desenvolvidas pelos docentes. Dessa forma, as identidades têm implicações diretas com a concepção de como o conhecimento é produzido em sala de aula; como e quais identidades são legitimadas nesse espaço social em que se defrontam identidades sociais marcadas pela cultura, pela história e pela instituição.

Baseada nas observações de aula e das entrevistas realizadas durante a pesquisa do Doutorado ${ }^{2}$, percebi que há na escola uma tentativa de "normalizar" os alunos e alunas da roça, inserindo-os em um modelo estabelecido. As tentativas de imposição do modelo, em especial do modelo escolar urbano, buscam a ideia da unidade identitária do que seria "o estudante, a estudante", selecionando apenas aqueles que conseguem adequar-se aos seus padrões. A relação com o outro é feita com base na adequação ao outro, e não em um movimento de alteridade e constituição de identidades.

Este artigo apresenta, baseado na realização de pesquisa etnográfica, experiências docentes vivenciadas na relação com o outro (aluno e aluna da

\footnotetext{
2 A pesquisa foi realizada nos anos de 2007 e 2008, resultando na tese intitulada Entre a Roça e a Cidade: Identidades, Discursos e Saberes na Escola.
} 
roça) apoiadas nas diferentes práticas discursivas/ pedagógicas observadas nos registros de cenas da sala de aula.

\section{Cenas da sala de aula: identidades e diferenças}

Fixar uma identidade como a norma é uma das formas privilegiadas de hierarquização das identidades e das diferenças. No caso da escola da cidade, a identidade do aluno e aluna da cidade é a norma, e a outra é a desviante. Constituída de representações imaginárias, a identidade do aluno e aluna da roça, na escola da cidade, se faz pela construção ficcional destes sujeitos pelos professores e professoras da cidade, via discurso. O discurso, nesse contexto, é algo poderosíssimo, delimitando as posições ocupadas pelos sujeitos na escola. Foucault (2004) aponta o sistema escolar como um dos mais relevantes mecanismos de apropriação social do discurso, ressaltando também que a escola tem-se constituído em um mecanismo de controle do discurso, impondo aos indivíduos que o pronunciam certo número de regras e não permitindo que todo mundo tenha acessos aos discursos.

Para dar conta das diferenças existentes na relação com o outro, Todorov (1993) apresenta três eixos nos quais pode ser situada a problemática da alteridade presente na sala de aula. Primeiramente, um julgamento de valor (um plano axiológico): o outro é bom ou mau; gosto dele ou não gosto dele. Visualizei esse julgamento na prática docente por meio dos estereótipos utilizados para os alunos e alunas, intitulando-os de fracos, bonzinhos, atrasados. Em segundo lugar, a ação de aproximação ou de distanciamento em relação ao outro (um plano praxiológico): adoto os valores do outro, identificome a ele; ou então assimilo o outro, impondo-lhe minha própria imagem. Entre a submissão ao outro e a submissão do outro há ainda um terceiro termo, que é a neutralidade, ou indiferença. $\mathrm{Na}$ sala de aula, observei isso em relação aos níveis de aprendizagem dos alunos e alunas. Havia "submissão" por parte dos professores e professoras ao perceberem alunos e alunas que se destacavam no processo ou, em sentido contrário, indiferença àqueles que demonstravam apatia ao processo de ensino-aprendizagem. Em terceiro lugar: conheço ou ignoro a identidade do outro (um plano epistemológico). Situo nesse eixo, com base nas práticas docentes observadas, a relação de distanciamento dos saberes dos alunos e alunos da roça ao se situarem como os responsáveis pelo saber legítimo, delineando apenas uma possibilidade de produção de conhecimento. Essas relações discursivas influenciam a constituição das identidades dos alunos e alunas da roça, conforme a maneira como esses e essas são inscritos nos discursos.

Podemos observar na fala da professora de Língua Portuguesa como ela retrata a adequação dos alunos e alunas da roça à escola da cidade: "Agora no dia a dia de sala de aula a convivência deles é normal." O efeito de sentido presente nesse discurso traduz-se na necessidade que os docentes têm de "incluir" o outro por meio do apagamento das fronteiras, das diferenças que singularizam o aluno e aluna da roça e os tornam "normais". A normalização é uma produção sutil de poder, determinando modelos, desvios, relações na sala de aula. Conforme Silva,

Normalizar significa eleger - arbitrariamente - uma identidade específica como o parâmetro em relação ao qual as outras identidades são avaliadas e hierarquizadas. Normalizar significa atribuir a essa identidade todas as características positivas possíveis, em relação às quais as outras identidades só podem ser avaliadas de forma negativa. A identidade normal é "natural", desejável, única. A força da identidade normal é tal que ela nem sequer é vista como uma identidade, mas simplesmente como a identidade. Paradoxalmente, são as outras identidades que são marcadas como tais. [...] A força homogeneizadora da identidade normal é diretamente proporcional à sua invisibilidade (2000, p. 83).

Em sala de aula a normalização determina o que aprender, como aprender, o material didático, a proposta pedagógica, o que é ser "alguém" na vida; enfim, marca as posições nos discursos e os sentidos que devem ser construídos. Levando essas reflexões para a sala de aula, observei que as práticas pedagógicas instituídas nesse espaço procuram normalizar os alunos e alunas da roça tomando-se por base as propostas, programas, livros didáticos, currículo, sistema e, acima de tudo, a ação isolada do sujeito-professor que não consegue visualizar outras referências de identidades, não vislumbra em 
sua prática o outro presente na interação, nem nos movimentos discursivos que promovem mudanças na ordem das coisas. O discurso "verdadeiro" do professor e da professora, o conhecimento legítimo, exames, classificações, estabelecem, por meio das redes de poder, padrões "normais" para os alunos e alunas da roça na escola da cidade. Isso produz o que Foucault (1979) chama de indivíduos "normalizados".

Ao observar e acompanhar onze docentes do Programa de Educação de Jovens e Adultos (EJA) durante um semestre letivo, pude constatar a busca pela "produção do mesmo" na escola, utilizando-se de aulas padronizadas, instituição da "verdade", falas distantes da realidade da roça, silêncios, saber escolar x saber da roça. Neste estudo, apresento a descrição de trechos de quatro aulas que mobilizaram mais intensamente os sentidos e significados presentes nas práticas discursivas/pedagógicas dos docentes sobre a constituição de uma identidade única, "normal" para os alunos e alunas da roça. Como podemos observar no registro abaixo da aula de Filosofia:

A professora inicia a aula distribuindo os alunos e alunas em duplas para lerem um texto sobre o "EU". O texto era lido e discutido por parágrafos. A professora fala sobre a importância de se identificar, de dizer quem cada um é, o que faz, o lugar da escola para ser alguém na vida. Os alunos e alunas nada dizem, não comentam o assunto. A professora introduz questionamentos depois da leitura do texto: 'Quem sou eu? O que é preciso para encarar a sua própria forma de ser? Como a escola me ajuda na vida . Alguns alunos e alunas respondem em voz baixa a pergunta, entre eles Mauri: 'Eu sou Mauri, do Pé do Morro '. A professora continua sua exposição oral: 'Cada um de nós tem uma história, vem de um lugar, de uma família, mas todos nós somos iguais, não existe diferença porque nós somos filhos do mesmo Pai'. A professora continua pedindo para que cada um escreva um pouco sobre sua história de vida. Ela pede para alguns alunos relatarem oralmente suas histórias de vida. Um aluno começa dizendo o que faz e quem é. A professora interrompe mostrando um roteiro geral para a construção da história que constava de: quem eu sou (nome, família), onde nasci (local, data, idade), o que faço (estudo, traba1ho), futuro (como posso ser alguém na vida, sair para cidades grandes, como mudar), dizendo que:
'Na hora de fazer o texto, vocês tem que mostrar as coisas importantes da vida de vocês - a família, a escola... No caso da escola, porque ela vai ajudar a ser alguém na vida' (Registro de aula retirado das anotações do diário de campo).

$\mathrm{Na}$ aula de Filosofia, a professora pretende trazer à tona uma discussão sobre identidade. Há um esforço de sua parte em mostrar para os alunos e alunas que é necessário saber quem cada um é, e a importância da escola nessa constituição. A forma como a professora conduzia a realização da atividade estabelecia a história a ser narrada e, consequentemente, a identidade que poderia ser revelada. A identidade foi circunscrita e concebida na sala de aula como uma essência - cada um é. Identificar-se, definir-se, eram ações fundantes para a formação do estudante, principalmente em razão do papel que a escola representava em torná-lo "gente".

O princípio da igualdade esteve sempre presente na aula como um potente instrumento de redenção e também como um instrumento de regulação. Era necessário que os alunos e alunas convivessem em igualdade; era necessário silenciar as diversidades para que a identidade única, fixa, pudesse ser claramente posta para cada um e cada uma que fizessem parte daquele lugar. Esse é um efeito de sentido que a aula produz no momento em que a docente institui a discussão do "Eu" como produtor de uma identidade essencialista do estudante e da estudante na escola da cidade. Essa delimitação silencia as identidades que não são incorporadas aos padrões educacionais vigentes. Isso por que os sujeitos que circulam no espaço escolar carregam consigo diferentes experiências de mundo, sobretudo os alunos e alunas oriundos da roça.

Nessa aula, percebemos que o outro precisa enquadrar-se na norma. Outras possibilidades de história de vida - ser alguém em locais distintos de cidades grandes, ser alguém na roça, estar sendo alguém naquele momento da produção na aula - são descartadas pela docente. O outro deve ser uma repetição do mesmo em que este é obrigado a converter-se à "mesmidade" para ser aceito no grupo. Especificamente no que se refere aos alunos e às alunas da roça, a "mesmidade" construída oculta as diferenças e mantém a irrelevância e invisibilidade desses sujeitos no espaço escolar. 
Outra aula que chamou bastante atenção foi a de matemática, em que o professor conduz a atividade mostrando o caminho de acesso ao saber escolar por meio de exemplos dados no quadro de giz. É apresentado um modelo a ser seguido, construído com base no "regime de verdade" instituído pela/ na escola.

O professor inicia a aula colocando exemplos do assunto no quadro de giz. Depois de explicar os exemplos dados, o professor apresenta a seguinte atividade: 'Agora vamos copiar um problema no caderno para ver se vocês conseguem responder como eu expliquei: O problema versava sobre a construção de uma parede por um pedreiro. Assim que o professor termina de 'ditar' o problema matemático, Marcelo apresenta a resposta. O professor faz o seguinte pedido a Marcelo: 'Faça como expliquei no quadro' Marcelo pergunta ao professor: 'A resposta tá errada?' O professor diz: 'Vá fazer como eu expliquei pra você aprender'. Os exemplos feitos pelo professor continuam no quadro de giz. $\mathrm{O}$ professor caminha pela sala, observando a atividade individualmente em cada carteira. No final da aula, os alunos e alunas são chamados a irem ao quadro de giz para responder ao problema. O professor diz: 'Você não quer vir Marcelo?' Ele responde: 'Eu só sei fazer conta de cabeça'. O professor chama outro aluno para responder o problema. Um aluno da cidade aceita: 'Eu vou, mas vou com o caderno' (Registro de aula retirado das anotações do diário de campo).

Um dos efeitos de sentido que a descrição da aula sugere é o delineamento da diferença nas formas de lidar com o saber escolar, o qual surge para Marcelo em uma aproximação que ele faz com o cotidiano, com o seu "saber da experiência" (LARROSA, 2002) e, sobretudo, com a "lida" na roça e com os saberes trazidos por seu pai, como podemos observar em sua história de vida: “[...] aprendi muitas coisa com ele [pai] na roça, até cubar a terra e fazer conta de cabeça". As formações discursivas de Marcelo, presentes em seu discurso nessa aula, revelam a sua identidade de filho de trabalhador rural e, consequentemente, os saberes oriundos desse lugar discursivo e simbólico que ele ocupa.

Os saberes vividos na roça, como contar sacos de feijão, milho, vender produtos agrícolas na feira e, sobretudo, realizar as cubações de terra ${ }^{3}$,

\footnotetext{
Estimativa sobre a área de um terreno.
}

estabelecem relações fecundas com o mundo da matemática, porém não são legitimados socialmente. Knijnik reflete sobre as contribuições desses saberes na produção dos conhecimentos da matemática com base nos estudos realizados pela etnomatemática ${ }^{4}$ :

[...] Da perspectiva da etnomatemática, existem também outras formas de produzir significados matemáticos, outras formas que são igualmente etnomatemáticas, manifestações simbólicas de grupos culturais como, por exemplo, as matemáticas das diferentes nações indígenas, a matemática de distintos grupos profissionais e aquela praticada pelas agricultoras e agricultores em suas atividades laborais (1997, p. 39).

Baseado na perspectiva da etnomatemática, é possível estabelecer diálogos entre a matemática e a cultura, opondo-se aos modelos tradicionais de ciência pautada na homogeneidade e universalidade do saber. A ideia de ciência posta na aula observada é pautada no paradigma da modernidade, centrado na razão e na concepção de sujeito homogêneo, consciente, universal, racional, em uma perspectiva de homogeneização das identidades, com verdade pronta, caminho único para acesso ao conhecimento, apenas uma lógica do conhecimento. É intensa a luta que a escola propõe aos alunos e alunas da roça a travar contra o "saber da experiência" (LAROSSA, 2002), contra aquilo que é desenvolvido como sabedoria de vida. A adesão dos alunos e alunas da roça aos conhecimentos científicos pressupõe a existência de outra racionalidade e de outra relação com o mundo rural, e, como efeito, a constituição de uma outra identidade.

$\mathrm{Na}$ aula de matemática, a ação de responder à questão imediatamente por meio de "contas de cabeça" revela o lugar ocupado no discurso por Marcelo. Ele fala do lugar do filho de pequeno agricultor, que aprendeu a raciocinar sobre a matemática a partir da semiótica produzida pela terra. Contudo, esse saber é desautorizado em sala de aula. O posicionamento discursivo do professor, ao pedir que siga o modelo exposto em seus exemplos no quadro de giz, revela uma crença na produção de via única do conhecimento matemático, a qual é feita por um grupo social autorizado socialmente

${ }_{4}$ Vertente da educação matemática que surge, na década de 1970, da análise de práticas matemáticas em diversos ambientes culturais. 
a produzir ciência. Essa é uma visão sobre o saber escolar tido como algo pronto, dado nos cursos de formação e que, na prática, na sala de aula, é aquele consagrado nos programas das disciplinas, materializado nos livros didáticos e ilustrado nos exemplos dados no quadro de giz.

O professor apresenta uma produção unilateral do conhecimento, apagando as diferenças reveladas em outras formas de significar a matemática. A interpretação é tida como única; não existem aí interpelações de vozes. Isso ocorre muito frequentemente na prática escolar por meio dos embates entre a interpretação "científica" dos docentes e o saber da experiência dos alunos e das alunas da roça. Essa relação estabelecida com o saber escolar modifica a experiência que os alunos e alunas da roça têm de si mesmos, dos seus lugares, dos seus saberes, produzindo outras identidades. Assim, eles silenciam e/ou abandonam os saberes que os constituem para compreenderem outra lógica, outra racionalidade.

Nesse modelo de prática pedagógica, o professor preocupa-se com o acúmulo de informações, sem levar em consideração os sentidos que perpassam todo esse processo de descoberta, os sujeitos que são descobertos pelo resultado da ação, a descoberta do outro. O outro passa a ser concebido como um "mesmo". Em vez de enfatizar a construção conjunta do saber legítimo mediante interação com os saberes dos alunos e alunas da roça, construídos com base em experiências concretas desses sujeitos, os docentes parecem optar pela regulação dos discursos por "verdades" científicas pautadas em uma racionalidade moderna, adotando formas normativas, institucionalizadas e ritualizadas de (re)produzir o conhecimento escolar.

Nos interdiscursos que circunscrevem as atividades, as explicações, os rituais, os discursos instituídos, há, em algumas aulas observadas, um desenho de aluno e aluna já posto. Os professores e professoras chegam à sala de aula com um perfil delineado do/da estudante, em que não se pressupõe que sejam sujeitos com/de conhecimento, há um vazio muito grande a ser preenchido pelo saber escolar. Assim, os docentes partem de um lugar discursivo para construírem um modelo que prevê identidades fixas, com configurações rígidas e posições estáveis. Dentro desse contexto, o perfil de aluno e aluna da cidade passa a ser a referência de identidade trabalhada na sala de aula.

A professora de Língua Portuguesa introduz o assunto da aula com charadas. A partir daí explica, exemplifica e questiona a turma sobre os gêneros literários. Em seguida, propõe uma produção textual baseada nas novelas, dizendo:

- 'Todo mundo sabe o que é uma novela?'.

Mauri responde: - 'Eu não, professora. Eu moro na roça e não tenho televisão'.

A professora continua: - 'Eu quero que vocês pensem em qualquer novela e escolham uma cena e montem uma narrativa'.

Os alunos e alunas, de uma maneira geral, reclamam da atividade. A professora diz:

\section{- 'Quem quiser pode trocar por um filme'.}

Mauri diz: —'Dá no mesmo, professora'.

A professora responde:-'Tente que você consegue. Novela e filme todo mundo conhece'.

Mauri e os demais colegas pegam os cadernos e fazem a produção. Peço à professora, no final da aula, para ver o texto de Mauri, e ela me mostra dizendo:

—_Olha, só fez ditos populares' (Registro de aula retirado das anotações do diário de campo).

Observei na aula de Língua Portuguesa que a professora pressupõe que todos e todas conheçam a novela, mas esse pressuposto causa inquietação em Mauri, demonstrando o seu descontentamento pelo exemplo não lhe ser algo comum, cotidiano, pois em sua casa não há energia elétrica. Então, em uma tentativa de produção do "mesmo", a professora constrói um modelo para produção textual baseado no universo urbano. Partir sempre do universo urbano como referência de conhecimento, de aprendizagem, parece ser algo comum e normal para os docentes. A justificativa que aparece nos interdiscursos dos professores é que a escola está situada na cidade, logo os alunos e alunas da roça devem adaptar-se a essa realidade. A aula revela também uma tentativa de Mauri em dizer quem ele é na sala de aula; identificar-se, estranhar a proposta, indicar a não-existência do comum (novela) em sua vida revelam um posicionamento de Mauri diante da diferença que o constitui, ou 
seja, questionar uma política da diferença que não autoriza outros lugares, outras práticas. Assim, a diferença, característica marcante da sala de aula, é apreendida no cotidiano escolar como expressão de um processo que precisa ser retificado e normalizado. A diferença adquire um valor negativo, devendo, portanto, ser eliminada para proporcionar um desenvolvimento satisfatório dos sujeitos e das relações, necessário à aprendizagem dos conteúdos escolares.

Essa prática discursiva desenvolvida pela professora traz a existência de alunos e alunas na sala de aula que não se enquadram no lugar predefinido pela escola como aquele que permite o ensinoaprendizagem. Especificamente para os alunos e alunas da roça, a escola da cidade não se organiza para acolhê-los, aceitando seus saberes, discursos, identidades que não se deixam circunscrever nos limites escolares. O espaço escolar configura-se em um território de passagem; assim, o processo vivido os coloca no "entre-lugar", em que sua dinâmica de aprendizagem indica resultados transitórios. Desse modo, constitui-se em um signo de contradição para a normalidade, um devir como afirmação de uma identidade itinerante. Na tentativa de individualizar, igualar, normalizar, a escola não permite que eles e elas vivam a dinâmica fluida, contraditória, deslizante, fronteiriça do "entre-lugar" em que se encontram, fazendo da aprendizagem um ato dialógico que confronta e embaralha permanentemente $o$ saber e o não-saber. No momento em que a escola classifica, insiste na produção do mesmo - o padrão que define a classificação - e na permanente reprodução do outro como o mesmo, apaga as singularidades, que sequer adquirem visibilidade no processo de ensino-aprendizagem. Tal processo marca a escolaridade em suas diversas dimensões, inclusive nas tarefas propostas, em que o outro apenas repete. Ao ser classificado, inscrito como o mesmo, suas potencialidades são circunscritas a um regime discursivo, que define o que é "verdade", o que é o saber e o não- saber. Enfim, eles e elas são posicionados diante da identidade de "ser da roça" para adquirirem outra identidade de aluno e aluna da escola da cidade. Assim, essas práticas discursivas regulam fazeres, dizeres e saberes dos alunos e alunas da roça, uma vez que, em uma perspectiva foucaultina, tornam-se dispositivos de governo e controle que determinam e produzem as identidades desses sujeitos.

Durante as observações, percebi a recorrência de assuntos próximos ao meu estudo nas atividades propostas por alguns professores e professoras; temáticas como urbano/rural, roça, identidade aparecem nas aulas com uma intencionalidade marcada pelo desvelamento e/ou velamento das produções identitárias dos alunos e alunas da roça com base nas práticas discursivas escolares. A aula de Geografia produz esse efeito de sentido, ainda que seja uma sequência do assunto já exposto; havia uma expectativa da professora que eu a observasse também na aula anterior.

A professora inicia suas atividades explicando que a aula será a continuação da aula anterior. Ela diz: -'Hoje a gente vai continuar a aula de ontem sobre a cidade e o campo, copiando o exercício'. Em seguida, a professora copia três questões no quadro de giz:

1) Qual a diferença entre cidade e campo?

2) O que mais chama atenção numa paisagem rural?

3) Cite paisagens construídas pelo ser humano.

A professora explica que o exercício deve ser respondido com base nas músicas trabalhadas na última aula. Enquanto os alunos e alunas respondem as questões, o silêncio é interrompido com uma pergunta de uma aluna:

\section{-'Professora, o que é queimada?'.}

Jucivalda responde: - 'É queimar o mato, fazer coivara'.

A professora retoma a pergunta dando exemplos de novas técnicas de substituição das queimadas e respostas presentes na música trabalhada. Os alunos e alunas continuam respondendo as questões. Jucivalda diz:

-'Mutirão, professora, também faz parte da zona rural. Eu mesma já fiz muito'.

A professora mantém-se em silêncio. Outra fala de Jucivalda:

—'Ah, milho assado é tão gostoso!'. Ela termina a atividade e ajuda alguns colegas que estão próximos.

A professora finaliza a aula "corrigindo" oralmente as questões: - 'O que diferencia a cidade da roça?'. 
Jucivalda responde: - 'As plantação'.

A professora insiste: -'E como se chama isto?'.

Jucivalda responde: - O'Os pés de planta que tem muito lá, as coisas que planta, a natureza que tem muito na roça e na cidade, não. Também tem muito bicho lá, a forma das pessoas viver também é diferente'.

A professora diz: 'A paisagem, o que diferencia é a paisagem'.

As outras questões são "corrigidas" e a aula é encerrada (Registro de aula retirado das anotações do diário de campo).

O conhecimento de Jucivalda, baseado em fontes orais, em experiência e em analogia do senso comum, não é legitimado na sala de aula. Ela utiliza-se de outra linguagem, revelando outros modos de produção de conhecimento. Demonstra, em suas intervenções orais, muita intimidade com o assunto, sentindo-se autorizada pela experiência que tem a ser a representante da roça naquela discussão. Jucivalda fala do lugar do sujeito que viveu a experiência concreta, que possui outros modos de vida, outros saberes, outras relações com o universo rural. Ou seja, suas experiências, sua história de vida, seus movimentos discursivos são fatores decisivos e determinantes na sua participação em sala de aula. Entretanto, há no interdiscurso presente na prática discursiva da professora, uma lógica da não-existência sobre essa produção do saber, que consiste na transformação da ciência, do saber escolar em critérios únicos de verdade.

Boaventura Santos (2004, p. 787) afirma que “[...] há produção de não-existência sempre que uma dada entidade é desqualificada e tornada invisível, ininteligível ou descartável de um modo irreversível". Há uma monocultura do saber na sala de aula. A produção do conhecimento é autorizada pela fala legítima da professora, pela resposta única, pela homogeneização dos sujeitos. Os alunos e alunas da roça acabam experienciando na escola da cidade as principais formas sociais de nãoexistência produzidas e legitimadas na sala de aula por meio da política de silenciamento dos seus saberes. Assim, os saberes da roça são tomados como obstáculos em relação às realidades tidas como importantes, produtivas, científicas, reforçando a ideia, na escola, de normalização.
Ao tentar diferenciar campo e cidade, Jucivalda traz uma busca de legitimação de um saber vivenciado cotidianamente. Sua resposta não se baseia apenas em um substantivo, em um nome, mas em um conjunto de situações adjetivadas que vão compondo uma interface do campo com a cidade. Nessa relação discursiva, encontra-se também a professora que coloca o saber escolar que possui sobre a disciplina como o elemento discursivo legítimo. Um dos efeitos de sentido que o trecho descrito da aula traz é que não se pode dizer qualquer coisa, nem dizer de qualquer maneira; há uma regulação do discurso, do saber, da identidade que é produzida com base nas práticas discursivas ali constituídas.

As questões e respostas da atividade pedagógica têm por objetivo produzir outras identidades nos alunos e alunas da roça, modificando a experiência que esses sujeitos têm de si, produzindo efeitos daquilo que Foucault chama de poder/saber, uma vez que saber e poder se implicam mutuamente: não há poder sem saber, nem saber sem poder. A relação poder/saber articula-se no discurso e, por conseguinte, é entendida como "[...] um jogo complexo e instável em que o discurso pode ser, ao mesmo tempo, instrumento e efeito de poder, e também obstáculo escolar, ponto de resistência e ponto de partida de uma estratégia oposta" (FOUCAULT, 1979, p. 96).

Todo discurso está ligado a efeitos de poder, os quais, por sua vez, constituem uma "política de verdade" em cada sociedade. São os tipos de discurso que a sociedade acolhe e faz circular como verdadeiros, e que funcionam como uma verdade coletiva. Os tipos de discursos aceitos que funcionam como verdadeiros na sala de aula garantem, por meio da constituição de regimes de verdade acerca do "fazer" do professor, a manutenção dos padrões tradicionais do exercício de poder na prática docente.

Ao desconsiderar os saberes que os alunos e alunas da roça possuem e procurar imprimir uma matriz de conhecimento, os docentes utilizam uma estratégia antropofágica que, segundo Bauman consiste em

[...] aniquilar os estranhos devorando-os e depois, metabolicamente, transformando-os num tecido indistinguível do que já havia. Era esta a estratégia da assimilação: tornar a diferença semelhança; abafar 
as distinções culturais ou lingüísticas; proibir todas as tradições e lealdades, exceto as destinadas a alimentar a conformidade com a ordem nova e que tudo abarcar; promover e reforçar uma medida, e só uma, para a conformidade (1998, p.29).

Em nome de um fazer científico, objetivo e preciso, a professora estabelece fronteiras discursivas e identitárias para Jucivalda diante do saber escolar. Os efeitos de sentido produzidos nas ações e falas da professora apontam para um distanciamento dos saberes da experiência apresentados pela aluna. $\mathrm{O}$ atravessamento do discurso da ciência aponta, de um lado, para a manutenção de certa cientificidade, que determina uma postura da professora diante dos saberes da roça. Essa realidade fez-me refletir sobre a natureza do saber escolar e sua relação com o contexto sociocultural em que se situam os alunos e alunas da roça, sujeitos desta pesquisa. Nesse contexto, em vez do reconhecimento da diferença, temos aqui o seu enquadramento, sua normalização, a reafirmação do "mesmo", do idêntico. Sobre este aspecto, Silva nos fala:

Respeitar a diferença não pode significar "deixar que o outro seja como eu sou" ou "deixar que o outro seja diferente de mim tal como eu sou diferente (do outro)", mas deixar que o outro seja como eu não sou, deixar que ele seja esse outro que não pode ser eu, que eu não posso ser, que não pode ser um (outro) eu; significa deixar que o outro seja diferente, deixar ser uma diferença que não seja, em absoluto, diferença entre duas identidades, mas diferença $d a$ identidade, deixar ser uma outridade que não é outra "relativamente a mim" ou "relativamente ao mesmo", mas que é absolutamente diferente, sem relação alguma com a identidade ou com a mesmidade (2000, p.101).

O processo de (de)marcação da diferença estabelecido nos discursos dos professores e professoras apresenta uma construção de fronteiras entre o que está dentro e o que está fora, um pertencimento discursivo simbólico acerca da escola. Nessa relação, os docentes procuram delimitar as "fronteiras" entre o saber do aluno e aluna da roça e o conhecimento da escola. Assim, a identidade é concebida como uma "positividade" - é uma questão de "ser" -, fruto da ideia de que a identidade é algo fixado pela origem (história, tradição). Contudo, compreendo que as identidades são definidas pela diferença, sendo resultado de um processo de produção simbólica e discursiva. Elas não são apenas conceituadas, são tramadas e impostas em meio a relações de poder produzidas nas relações sociais.

\section{Considerações finais}

As práticas discursivas dos professores e professoras observadas traduzem um desejo em tornar iguais os diferentes. As condições de produção dos referidos discursos marcam o lugar de onde falam esses docentes, o que representam no momento em que estabelecem os modelos a serem seguidos, as respostas autorizadas, sendo possível observar uma negação do outro (aluno, aluna), tomando-o como aquele que não sabe e que não quer nada com o saber escolar, impedindo que os alunos e alunas da roça possam se ver nesse percurso como sujeitos produtores do conhecer, dos sentidos que movimentam a escola e a sociedade de uma forma geral. Assim, os alunos e alunas da roça sentem dificuldade em adaptar-se à escola da cidade, pois nesse espaço seus valores, saberes e identidades não são aceitos nem validados. Entretanto, como sujeitos que possuem identidades múltiplas e não fixas como afirma a escola, os alunos e alunas inseridos na produção da "mesmidade", na classificação, na normalização, habitam identidades, negociam, deixam fluir a "outridade" presente no movimento fluido da constituição das identidades. Como nos diz Silva (2000, p.79), “[...] a mesmidade (ou a identidade) porta sempre o traço da outridade (ou da diferença)".

A tendência evidenciada na sala de aula privilegiava a distância, a ruptura e, em alguns casos, a negação explícita dos saberes sociais, dos saberes da experiência, da "ciência" da roça. Pude perceber neste estudo que é, sobretudo, na sala de aula que se desvelam as identidades dos alunos e alunas da roça, constituindo as imagens que os professores e professoras produzem sobre esses sujeitos, ou seja, baseadas nas formações imaginárias presentes nas práticas discursivas desenvolvidas. Há uma produção simbólica e social sobre o aluno e a aluna da roça projetada com base em um imaginário coletivo que os inscreve em uma determinada posição nos discursos. 


\section{REFERÊNCIAS}

BAUMAN, Zygmunt. O mal-estar da pós-modernidade. Rio de Janeiro: Jorge Zahar, 1998.

FOUCAULT, Michel. Microfísica do poder. Tradução de Roberto Machado. Rio de Janeiro: Graal, 1979.

. A ordem do discurso. Tradução de Laura Fraga de Almeida Sampaio. 11. ed. São Paulo: Loyola, 2004.

KNIJNIK, Gelsa. As novas modalidades de exclusão social: trabalho, conhecimento e educação. Revista Brasileira de Educação, São Paulo, n. 4, p. 35-42, 1997.

LARROSA, Jorge Bondía. Notas sobre a experiência e o saber de experiência. Tradução de João Wanderley Geraldi. Revista Brasileira de Educação, São Paulo, n. 19, p.20-28, jan./abr. 2002.

SANTOS, Boaventura de Sousa. Um discurso sobre as ciências. 2. ed. São Paulo: Cortez, 2004.

SILVA, Tomaz Tadeu da (Org.). Identidade e diferença: a perspectiva dos estudos culturais. Petrópolis: Vozes, 2000 .

TODOROV, Tzvetan. A conquista da América: a questão do outro. Tradução de Beatriz Perrone Moisés. São Paulo: Martins Fontes, 1993.

Recebido: 24.05.2011

Aprovado: 15.08.2011 